\title{
Erratum to: Synthesis and antioxidant activity of a new class of sulfone/sulfonamide-linked bis(oxadiazoles), bis(thiadiazoles), and bis(triazoles)
}

Adivireddy Padmaja • Devanaboina Pedamalakondaiah • Gundala Sravya · Guda Mallikarjuna Reddy •

Malaka Venkateshwarulu Jyothi Kumar · Ch. Appa Rao

Published online: 22 November 2014

(C) Springer Science+Business Media New York 2014

Erratum to: Med Chem Res

DOI 10.1007/s00044-014-1277-5

In the original version of this article, Ch. Appa Rao is included in the acknowledgements section. He should instead be credited as the final author of the article. His name is now included in the author group.

The online version of the original article can be found under doi:10.1007/s00044-014-1277-5.

\footnotetext{
A. Padmaja $(\bowtie)$ D D. Pedamalakondaiah · G. Sravya ·

G. M. Reddy

Department of Chemistry, Sri Venkateswara University,

Tirupati 517502, Andhra Pradesh, India

e-mail: adivireddyp@yahoo.co.in

M. V. J. Kumar

Department of Biotechnology, Sri Venkateswara University,

Tirupati 517502, Andhra Pradesh, India

Ch. Appa Rao

Department of Bio-Chemistry, Sri Venkateswara University,

Tirupati 517502, Andhra Pradesh, India
} 